\title{
XXI. Observations on the house-spider, in reply to a statement in the Zoological Journal, quoted in the Phil. Mag. and Annals, vol. x. p. 184
}

\author{
John Blackwall Esq. F.L.S.
}

To cite this article: John Blackwall Esq. F.L.S. (1832) XXI. Observations on the house-spider, in reply to a statement in the Zoological Journal, quoted in the Phil. Mag. and Annals, vol. x. p. 184, Philosophical Magazine Series 3, 1:2, 95-98, DOI: 10.1080/14786443208647843

To link to this article: http://dx.doi.org/10.1080/14786443208647843

曲 Published online: 01 Jun 2009.

Submit your article to this journal $[\pi$

Џ Article views: 2

View related articles 
state a similar appearance, in its specimens of burnt, yellow and red clay, and white and red clay-stone, to that at the point (b.) And in the present month of September, I also found that at the point $(d)$ there had been a considerable portion of the cliff under combustion; and large fragments of slag and vitrified clay-stone were picked up on its surface.

The circumstance of these three points $b, c$, and $d$ being situated each in the immediate vicinity of coal-beds, renders it highly probable that their combustion is to be attributed to a subjacent seam of coal having become ignited, and communicating its flame to the inflammable materials with which they were supplied.

I may here observe, that after a strong south-east gale the shore on this coast is strewed both with small and large rounded fragments of pumice-stone, of four varieties of colour; white, ash-gray, brown, and black. In its texture this pumice bears a striking resemblance to that variety of this mineral which abounds on White Island, aconstantly active volcano, 40 miles to the north of the East Cape of New Zealand; and it may be a question of interest, whether these fragments of pumice are conveyed to these shores from thence, or detached and borne on the waves from some submarine volcano in our more immediate neighbourhood.

The strand on this coast, in many parts composed of sandstone, millstone-grit, and pudding-stone, mixed with ironstone, is singularly divided in several instances into sections resembling rail-roads; and in one spot it is covered with circular masses, much water-worn, in figure resembling those of a curious formation of sandstone discovered by me in Glendon Brook, Hunter's River, and described in a memoir read before the Philosophical Society of Cambridge in the month of March 1830.

Sept. 23rd, 1831.

XXI. Observations on the House-Spider, in reply to a Statement in the Zoological Journal, quoted in the Phil. Mag. and Annals, vol. x. p. 184. By JoHn Blackwali, Esq. F.L S. \&c.*

NUMEROUS experiments made with the House-spider (Aranea domestica), under a great variety of circumstances, have induced me to believe that it is not endowed with the instinct to let out lines from the spinners, over which it can escape from captivity, when placed on a twig insulated by water and exposed to a current of air. This opinion, which is published in the Philosophical Magazine and Annals, vol. $x$.

* Communicated by the Author. 
p. 184, has elicited an editorial note having reference to an article in theZoologicalJournal, vol. i. p. 283-284, from which, on a hasty perusal, it might be supposed that this instinct is sometimes manifested by the house-spider when so situated. But as it must be conceded, on mature deliberation, that an inference precipitately deduced from a single, and, on the writer's own showing, unsatisfactory experiment, cannot be considered as at all invalidating the conclusion at which $I$ have arrived after a careful and extensive investigation of the subject, I should scarcely have deemed it requisite to bestow a comment on what he has written, had I not felt called upon to do so by the allusion made to it in the above-named scientific publication. Unforeseen obstacles, which it would be tedious to particularize, have concurred to prevent me carrying my intention into effect so early as I could have wished.

In order that the statement of this observer, whose views in more instances than one are opposed to my own, may be duly appreciated, I shall transcribe it at length, offering at the same time such animadversions upon it as a candid examination of its claims to the attention of naturalists has suggested.

"Some years ago," he remarks, "when making some observations on the habits of spiders, I was struck with the following circumstance, which $I$ have never found in any author on the subject. I insulated a common house-spider, by placing it on a little platform, supported by a stick with a weight at the bottom, in the middle of a rummer of water. The platform was about half an inch above the surface, which was nearly even with the top of the glass. It presently made its escape, as was anticipated, by suffering a thread to be wafted to the edge of the glass; but supposing that it might have been assisted by the water being so nearly on the same level, 1 poured some of it away, and placed the spider as before. It descended by the stick till it reached the water, and examined with its two anterior feet all round, but finding no way to escape, it returned to the platform, and for some time prepared itself by forming a web, with which it loosely enveloped the abdomen, by means of the hinder legs. It then descended, without the least hesitation, into the water, to the bottom; when I observed the whole of the abdomen covered with a web containing a bubble of air, which I presume was intended for respiration, as it evidently included the spiracles. The spider, enveloped in this little diving-bell, endeavoured on every side to make its escape, but in vain, on account of the slipperiness of the glass; and after remaining at the bottom of the water for thirteen minutes, it returned apparently much exhausted, for it immediately coiled itself closely under the little platform, and remained afterwards without motion. This 
property of forming for itself a reservoir of air, by means of which it is preserved under water, is somewhat analogous to the interesting habit of the Argyroneta, although it serves for a different purpose. In the present case, it is doubtless intended to enable the animal to cross the water with safety."-T.B.

Notwithstanding the boldness of the author's assertion, that the spider, in the experiment cited above, made its escape " by suffering a thread to be wafted to the edge of the glass," it is apparent from his employing the phrase, " as was anticipated," that he had previously received a bias which disqualified him for giving an impartial opinion in a case so defective in evidence as the one under consideration. I say so defective in evidence, because it may be fairly presumed that the escape of the spider was not witnessed by the experimenter, who even admits the possibility of the animal having derived assistance from the water, in consequence of its being nearly on a level with the top of the glass. Now the only manner in which the spider could accomplish its purpose by means of the water would be by traversing its surface; and that it actually did so can scarcely be doubted,-for we are informed that when some of the water was poured away, its plan of operations was speedily changed, and every attempt made to regain its liberty proved unavailing.

Additional weight is given to this conclusion by facts which have fallen under my own observation. Various kinds of spiders are known to run upon water with greater facility than they do on land; and though the larger of our indigenous species, including the Aranea domestica, are, at least when they have attained their full growth, incapable of doing so, still they sometimes contrive to effect a passage over its surface by the following ingerious expedient. Placed on a twig insulated by water they attach a line to it, which they seize with the foot of one of the hind legs, allowing it to run freely through the claws as it proceeds from the spinners. Descending to the surface of the liquid they use their best endeavours to pass over it; and should a little dust or other extraneous matter happen to rest upon it, enabling them to obtain even a slight footing, their efforts are frequently crowned with success; the line, which chiefly contributes to support them during their progress, and also serves to secure a return to the twig, should their attempts prove abortive, being ultimately made fast to the edge of the vessel containing the water. It is most probable, therefore, that the line which our author affirms was wafted to the edge of the glass, had been conveyed to it in the manner just described.

When spiders descend beneath the surface of water, a bubble Third Scries. Vol. 1. No. 2. Aug. 1832. 
of air is usually seen to envelop the abdomen. Misled by the appearance of the bubble, in the case of the house-spider, which was the subject of his experiment, the author of the article in the Zoological Journal endeavours to account for this fact on the supposition that the air is contained in a web formed about the body of the spider with the assistance of the hinder legs. Those zoologists who are familiar with the external structure of spiders will immediately perceive the insufficiency of this explanation: it will be equally apparent also to the uninitiated, when they are informed, that the cephalothorax and even the legs individually, as well as the abdomen, are frequently encompassed with air. In short, the air, which in the form of bubbles envelops to a greater or less extent the body and limbs of spiders when immersed in water,-instead of being contained in a web, is confined among the hair with which those animals are clothed; consequently, however sudden or unexpected their submersion may be, they are always prepared for it, as I have ascertained by repeated trials.

With these results before us, it will be readily admitted, that in conducting experiments with spiders placed on objects insulated by water, there is a decided advantage in employing, as I uniformly do, vessels having smooth perpendicular sides; care being taken not to $f i l l$ them with the liquid. Moreover, when the experiments are made with hunting spiders, a vessel of considerable internal dimensions should be selected; for if this precaution be neglected, some species, Salticus scenicus for example, will escape by leaping over the water intended to confine them; and as on such occasions a line attached by its extremity to the station previously occupied by each individual, is drawn out after it from the spinners, the notion that it had been wafted to the edge of the vessel by a current of air, might be induced in this case, as it was in that of the house-spider, to an exposition of which so large a portion of the present communication is devoted.

XXII. Particulars of the Measurement, by various Methods, of the Instrumental Error of the Horizon-Sector described in Phil. Mag. vol. lix. By John Nixon, Esq.*

[Continued from Phil. Mag. and Annals, N.S. vol. x. p. 347.]

\section{By the Sixth Method.}

Theory.-THE elevation of a mountain, observed from a station at its base, should be found, on transporting the instrument to its summit, to be equal to the cor-

* Communicated by the Author. 